\title{
Improving Students Engagement Through Active Learning Strategies: Case study based Active Review Sessions and Skillathon
}

\author{
Sachin S. Patil ${ }^{1}$, Nagaraj V. Dharwadkar ${ }^{2}$ \\ ${ }^{1}$ Computer Science and Engineering Department, Rajarambapu Institute of Technology, Rajaramnagar \\ ${ }^{2}$ Computer Science and Engineering Department, Rajarambapu Institute of Technology, Rajaramnagar \\ ${ }^{1}$ sachin.patil@ ritindia.edu \\ ${ }^{2}$ nagaraj.dharwadkar@ritindia.edu
}

\begin{abstract}
Today's z-generation student is more captivated with hand-held devices involving e-participation such as virtual games, Github repository creation, e-netizen and many more. It implicitly points towards participative learning through engagement. There is a need in shift of paradigm wherein the teaching-learning strategy should emphasize for student's participation to increase concrete learning. The proposed experimentations in this work is to share two active learning strategies viz. Case study based Active Review Sessions and Skillathon, which have practiced and experienced during the delivery of B Tech and $\mathrm{M}$ Tech courses. These two methodologies have been chosen with certain motivations to improve student's engagement for learning, elevate collaborative learning together with complying Outcome based Education (OBE). Additionaly, they have helped to retain the experienced knowledge with joyful status. These techniques were guided with some definite suitability to address the prior discrepancy of course attainments and improve its outcome. The students were found ardent in participative learning connecting these strategies. The post activity analysis has shown a notable rise in student's performance.
\end{abstract}

Keywords: Active learning strategies, Case study based Active Review Sessions, Skillathon, Outcome based Education, Collaborative learning skills

\section{Introduction}

Student learning tends to various dimensions including reflective, intuitive and experimental approaches. It has been scientifically analysed that the students learning fundamentally depends on his/her inherent ability along

\section{Sachin Patil}

Computer Science and Engineering Department, Rajarambapu Institute of Technology, Rajaramnagar sachin.patil@ ritindia.edu

with the learning style [1]. Teaching methodologies has to subsume them by focusing on principle needs while improving basic understanding. Additionaly, maintaining a dynamic environment within large classrooms is a major challenge. The objective of delivering a concept in an hour lecture should be intact with solving a case study based practical problems. It will indirectly help to improve the joy of learning.

The study of various learning abilities has stated two observations viz. student's role is almost passive and the concentration of individual fades off after every 18-20 minutes gap [2]. Less involvement with more theoretical approach deteriorates learning over memorization. The proposed active learning strategies viz. Case study based Active Review Sessions and Skillathon [3] assist in improving involvement which discreetly inclines to learn the concept and course effectively.

Particulars of methodologies applied to respective courses are as follows (2018-19):

1. Case study based Active Review Sessions:

i. Sem. - I - Third Year B. Tech.: Database management Systems

ii. Sem. - II - Final Year B. Tech.: Big Data Analytics (Program Elective) and First Year M. Tech.: Machine Learning (Program Elective)

\section{Skillathon:}

- Sem. - II - Final Year B. Tech.: Big Data Analytics (Program Elective)

The attempt was to transform the idle environment of large classroom into collaborative cum participative nature while improving learning outcomes. Further, the outline of paper is described as section II discusses Active Learning Strategies, section III deals with analysis and issues while conduction in section IV. Finally, the section V discourse the outcomes in terms of conclusion.

\section{Active Learning Strategies}

The detail procedure of both strategies for the respective courses is provided as follows:

\section{A. Case study based Active Review Sessions}

The detail steps of case study based active review sessions are represented in Fig. 1. The figure supports to portray the bench-wise solution for the given problem/concept. Each row has to provide the desired solution to forward it to its peer group for next stage solution till the final solution. At 
last the respective groups have to discuss their learning in peer discussion to understand the overall design of solution.

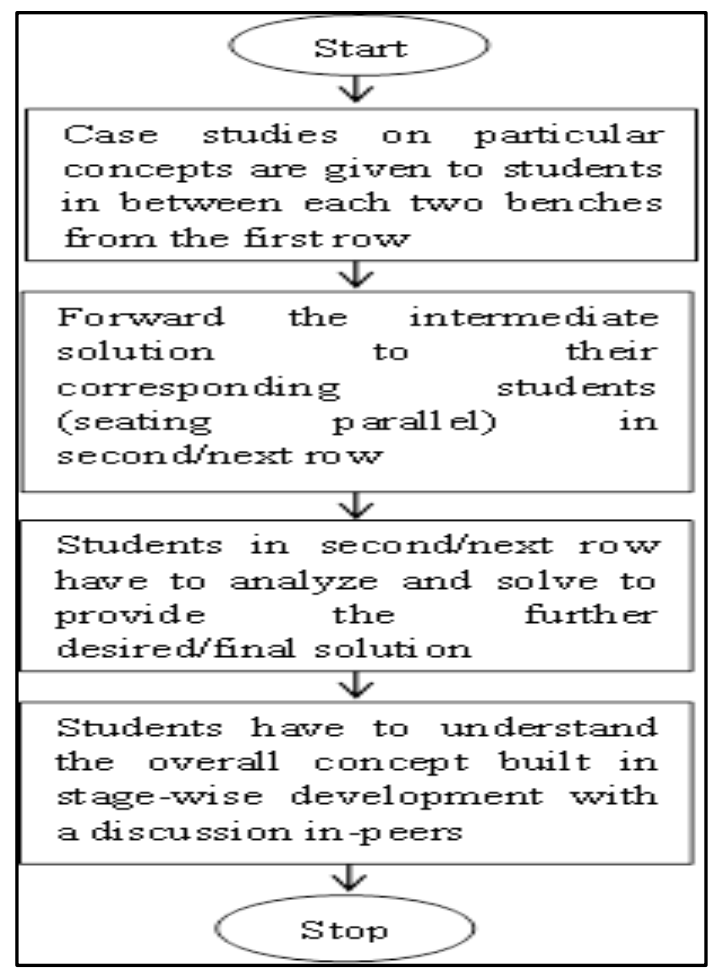

Fig. 1 Case study based Active Review Session

1) Sem. - I - Third Year B. Tech.: Database management Systems for Normal forms:

a. Case studies on Normalization are given to students in between each two benches from the first row.

o Analyze and solve the de-normalized tables in to 1-NF o Forward the intermediate solution to their corresponding students (seating parallel) in second row

b. Students in second row have analyze and solve to provide the $2-\mathrm{NF} / \mathrm{BCNF}$

oForward the intermediate solution to their corresponding students in third row

c. Students in third row have analyze and solve to provide the 3-NF

oForward the intermediate solution to their corresponding students in fourth row

d. Students in fourth row have analyze and solve to provide the 4-NF

At the end of this activity student have understood how Normalization of database helps for Good and concrete database design.

2) Sem. - II - Final Year B. Tech.: Big Data Analytics for SQL to NoSQL forms: a. Case studies on Normalization are given to students in the first column.

$\circ$ Analyze and solve to provide the de-normalized tables in to 3-NF

oForward the intermediate solution to their corresponding students (seating parallel) in second column

b. Students in second corresponding column have investigate and explain to offer the NoSQL design comprising semi/un-structured data

o Forward the intermediate solution to their corresponding students in third column

c. Students in third row have examine and resolve to deliver the solution incorporating Big Data Analytics Ecosystem

At the end of this activity student have comprehend how do Normalization of database helps for Good and concrete design and its underlying bed for experimental analysis.

3) Sem. - II - First Year M. Tech.: Machine Learning for Regression/Classification based modeling:

a. Case studies for Regression/Classification have given to students in the first column/peer member

o Analyze and solve to provide the modeling of concept oForward the intermediate solution to their corresponding students (seating parallel) in second column/peer member

b. Students in second column/peer member have investigate and explain to offer the concrete explanation of case study complying the model \& its critical analysis

\section{B. Skillathon}

The stage-wise details of Skillathon activities are represented in Fig. 2. The figure helps to depict the formation of groups comprising selectee's to attempt quiz and forming quiz. The role of selectee's to attempt MCQ's and further compete for evaluation is stated in detail below.

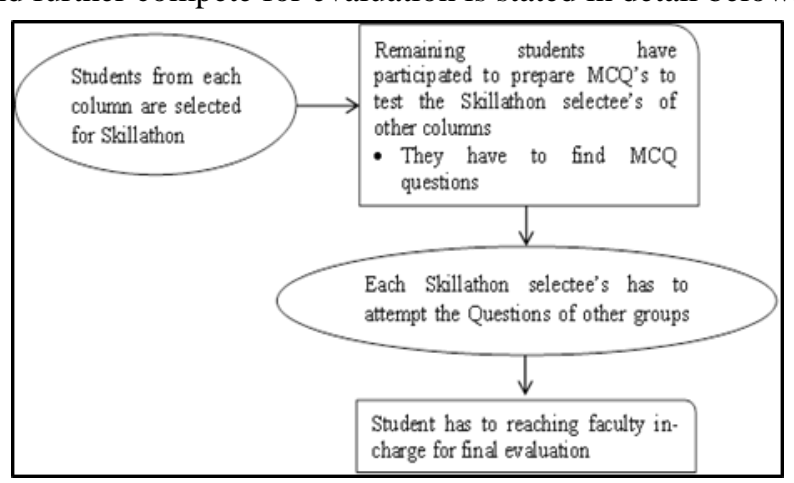

Fig. 2 Skillathon

- Sem. - II - Final Year B. Tech.: Big Data Analytics

a. 3 students from each column are selected for Skillathon 
b. Remaining students have participated to interrogate the learning capacities (technical) of Skillathon selectee's. They have found 15 IMP questions over first 5 units.

c. Each Skillathon selectee's has to pass questions rounds from three remaining groups. They have got bonus of $50 \%$ reduction in questions (optional) at next level if they complies $100 \%$ right question in every previous round. Crossing criteria per-round is of $70 \%$ correct answers except last stage. (For bonus - A round is given on yellow chit for stage-I and a circle for stage-II with the sign of faculty in-charge)

d. Student reaching faculty in-charge will be finally evaluated for winning the race based-on $70 \%$ for score gained \& $30 \%$ for reaching destiny.

Will help to prepare for MCQ along with overall revision.

\section{Review and Analysis}

The students have collaboratively participated for both of the strategies discussed above. There was a group wise cohesive response of students for each scheduled activity.

Student's involvement and outcomes for the individual methodology at the respective courses is provided as follows:

A. Case study based Active Review Sessions: Responses and Observations

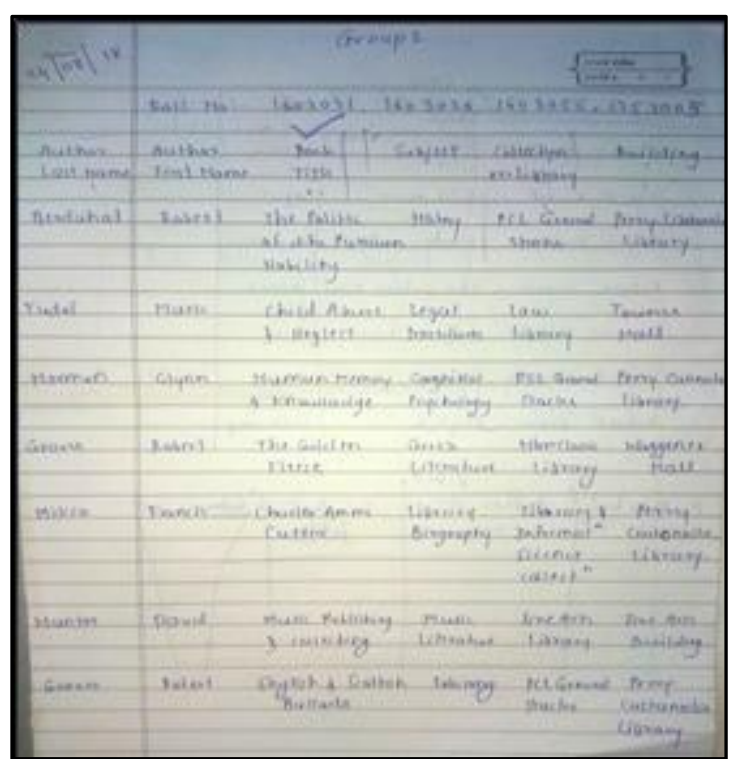

Fig. 3 Case Study responses for normal forms- Group 1

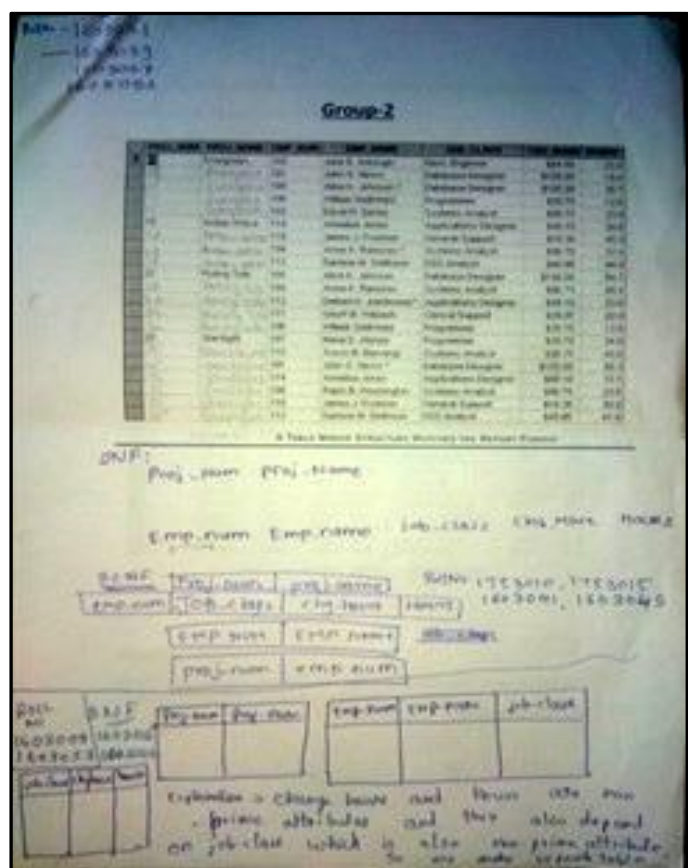

Fig. 4 Case Study responses for normal forms- Group 2

The sheets in Fig. 3 and Fig. 4 are stating the responses of Third Year B. Tech. students while handling the case studies to provide a normalized database design by transforming the table design to $3-\mathrm{NF}$.

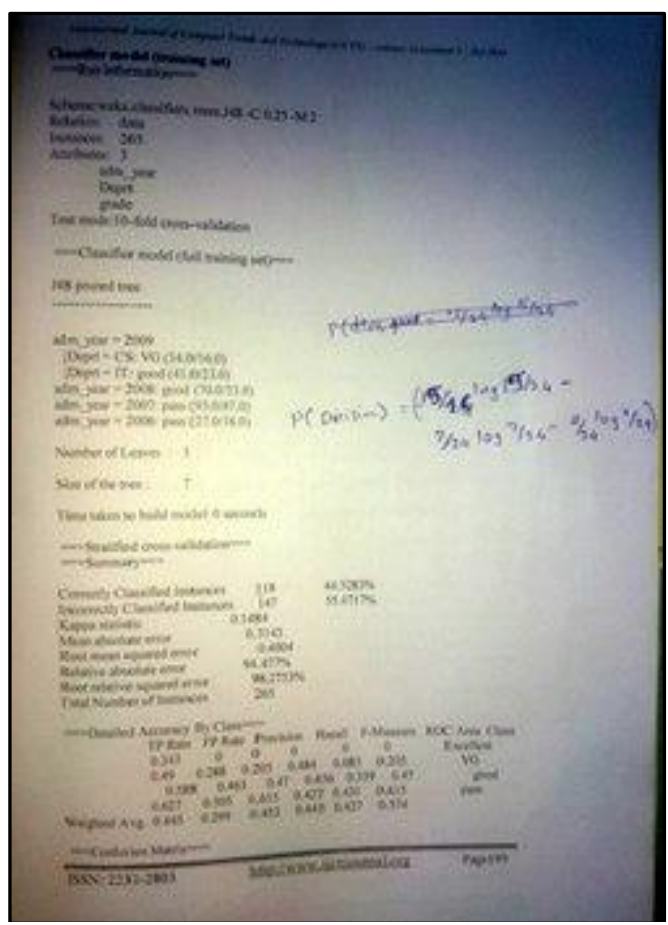

Fig. 5 Case Study responses for Classification modeling - Group 1 


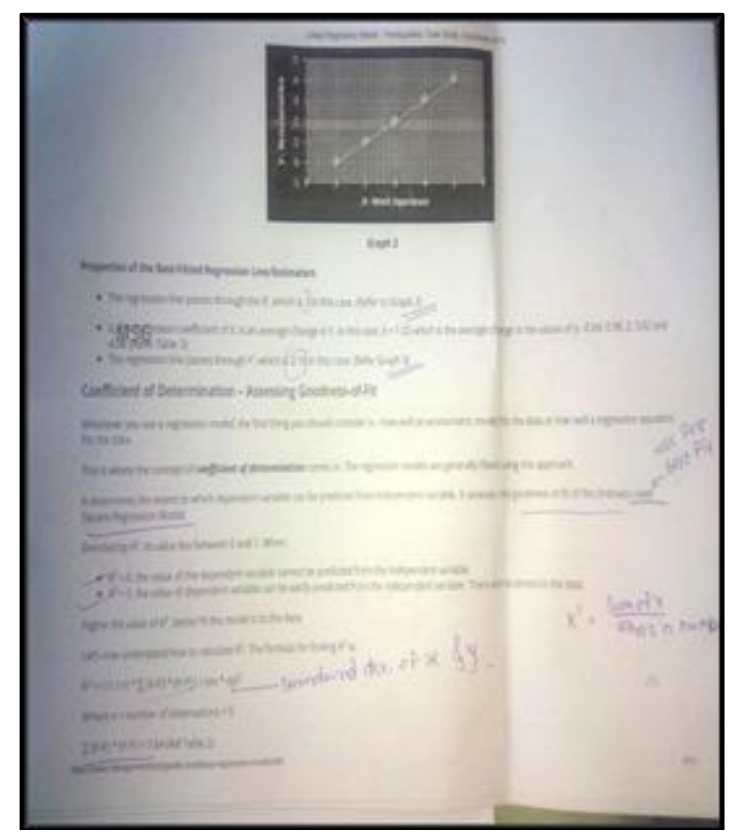

Fig. 6 Case Study responses for Regression modeling - Group 2

The sheets in Fig. 5 and Fig. 6 are stating the responses of First Year M. Tech. students while handling the case studies to provide a normalized database design by transforming the table design to $3-\mathrm{NF}$.

There are some tangible and intangible observational outcomes at the respective courses. They are depicted as follows:

- Intangible:

- Collaborative learning

- Team work

- Tangible:

Table 1. Attempt of Questions Related to Normal Forms

\begin{tabular}{|c|c|c|c|c|}
\hline $\begin{array}{r}\text { Exam } \\
\text { Type }\end{array}$ & Q. no. & $\begin{array}{c}\text { Total no. } \\
\text { of } \\
\text { Students }\end{array}$ & $\begin{array}{c}\text { No. of } \\
\text { Students } \\
\text { Attempted } \\
\text { Q. }\end{array}$ & $\begin{array}{c}\text { Avg. } \\
\text { Marks } \\
\text { (Out of) }\end{array}$ \\
\hline UT-2 & 1.b) Optional & 78 & 53 & $4.3(6)$ \\
\hline ESE & 2.b) & 78 & 75 & $5.6(7)$ \\
\cline { 2 - 2 } & 3.b) Optional & & 59 & $4.5(6)$ \\
\cline { 5 - 5 } & & & & \\
\hline
\end{tabular}

- UT - Unit Test, ESE - End Semester Exam

Table 2. Attempt of Questions Related to SQL to NoSQL

\begin{tabular}{|r|c|c|c|c|}
\hline $\begin{array}{r}\text { Exam } \\
\text { Type }\end{array}$ & Q. no. & $\begin{array}{c}\text { Total no. } \\
\text { of } \\
\text { Students }\end{array}$ & $\begin{array}{c}\text { No. of } \\
\text { Students } \\
\text { Attempted } \\
\text { Q. }\end{array}$ & $\begin{array}{c}\text { Avg. } \\
\text { Marks } \\
\text { (Out of })\end{array}$ \\
\hline UT-2 & 1. b) Optional & $24(26)$ & 14 & $4.1(6)$ \\
\hline
\end{tabular}

Table 3. Attempt of Questions Related to

Regression/Classification based Modeling

\begin{tabular}{|r|c|c|c|c|}
\hline $\begin{array}{r}\text { Exam } \\
\text { Type }\end{array}$ & Q. no. & $\begin{array}{c}\text { Total no. } \\
\text { of } \\
\text { Students }\end{array}$ & $\begin{array}{c}\text { No. of } \\
\text { Students } \\
\text { Attempted } \\
\text { Q. }\end{array}$ & $\begin{array}{c}\text { Avg. } \\
\text { Marks } \\
\text { (Out of) }\end{array}$ \\
\hline
\end{tabular}

\begin{tabular}{|c|c|c|c|c|}
\hline UT-2 & 1. a) Optional & $8(9)$ & 4 & $4.6(6)$ \\
\hline & 2.b) & $8(9)$ & 8 & $4.3(6)$ \\
\hline
\end{tabular}

The number of attempts for questions related to considered concepts (Normal forms, SQL to NoSQL and Modeling) was above $70 \%$ even in-case of optional questions (Table 1 to 3 ). Similarly the $\%$ of attempt for compulsory questions is seen to be near to $93 \%$ involving both types of exams (UT and ESE). The values in Table 1 to 3 have provided an insight that the percentage of students attempting the questions related to the projected concepts has increased. Correspondingly the average marks have aided to depict the rise in marks along with improving the attainment of course outcome (the $\%$ of marks attainment is approximately near to $70 \%$ in average).

\section{B. Skillathon: Responses and Observations}

The response for this technique was an activity conducted during the lecture slot. As per stated procedure in section 2 . $\mathrm{B}$, the students were pre-selected 10 days before the activity as the representatives of groups and others members of group were informed to prepare the MCQ based questionary. The activity was conducted and recorded on $10^{\text {th }}$ April 2019 with three groups.

The sample of MCQ's created by group 2 are as follows:

1. Hadoop is a framework that works with a variety of related tools. Common cohorts include:
a. MapReduce, Hive and HBase
b. MapReduce, MySQL and Google Apps
c. MapReduce, Hummer and Iguana
d. MapReduce, Heron and Trumpet

2. ___ is a platform for constructing data flows for extract, transform, and load (ETL) processing and analysis of large datasets.
a. Pig Latin
b. Oozie
c. Pig
d. Hive

3. Mapper implementations are passed the JobConf for the job via the method
a. JobConfigure.configure
b. JobConfigurable.configure
c. JobConfigurable.configureable
d. None of the mentioned

4. The output of the ___ is not sorted in the Mapreduce framework for Hadoop.

a. Mapper 

b. Cascader
c. Scalding
d. None of the mentioned

5. HDFS and NoSQL file systems focus almost exclusively on adding nodes to:
a. Scale out
b. Scale up
c. Both Scale out and up
d. None of the mentioned

6. Point out the correct statement :
a. DataNode is the slave/worker node and holds the user data in the form of Data Blocks
b. Each incoming file is broken into $32 \mathrm{MB}$ by default
c. Data blocks are replicated across different nodes in the cluster to ensure a low degree of fault tolerance
d. None of the mentioned

7. Point out the wrong statement :
a. Replication Factor can be configured at a cluster level (Default is set to 3 ) and also at a file level
b. Block Report from each DataNode contains a list of all the blocks that are stored on that DataNode
c. User data is stored on the local file system of DataNodes
d. DataNode is aware of the files to which the blocks stored on it belong to

8. Point out the correct statement :

a. Avro provides functionality similar to systems such as Thrift

b. When Avro is used in RPC, the client and server exchange data in the connection handshake

c. Apache Avro, Avro, Apache, and the Avro and Apache logos are trademarks of The Java Foundation

d. None of the mentioned

9. Which of this is not a scheduler options available with YARN?
a. Optimal Scheduler
b. FIFO scheduler
c. Capacity scheduler
d. Fair scheduler

10. The Hadoop tool used for uniformly spreading the data across the data nodes is named:

a. Scheduler
b. Balancer
c. Spreader
d. Reporter

11. Using peer-to-peer replication and sharding is a common strategy for databases.
a. Hierarchical
b. Parallel
c. distributed
d. None

12. Map Tasks output is written to
a. Jobtracker
b. Local Disk
c. Tasktracker
d. HDFS

13. The operaror is used to view the map-reduce execution plans.
a. DESCRIBE
b. EXPLAIN
c. STORE
d. DUMP

14. The archive file created in hadoop always has extension
a. .hrc
b. har
c. .hrh
d. .hrar

15. The current version of Hadoop is
a. 2.7 .6
b. 2.7 .7
c. 2.7 .8
d. 2.7 .9 


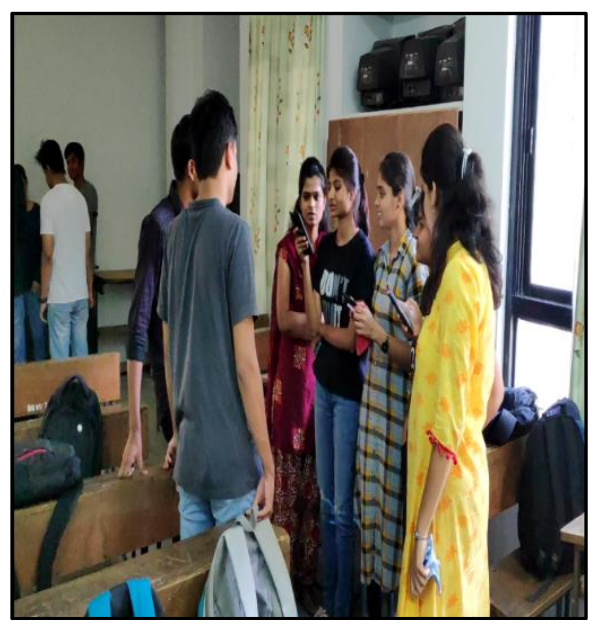

Fig. 7 Skillathon response - Group 1

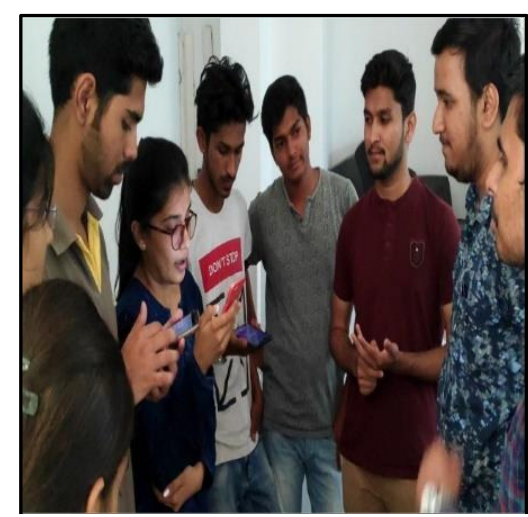

Fig. 8 Skillathon response - Group 2

The snaps of video in Fig. 7 and Fig. 8 evidence the responses of Final Year B. Tech. students while experimenting the active learning technique while facing the other teams and competing for Skillathon.

There are several tangible and intangible observational outcomes at the B. Tech. Big Data Analytics course. They are depicted as follows:

- Intangible:

- Collaborative learning

- Team work

- Tangible:

Table 4. Attempt of Questions

\begin{tabular}{|c|c|c|c|c|}
\hline $\begin{array}{r}\text { Exam } \\
\text { Type }\end{array}$ & $\begin{array}{c}\text { No. of } \\
\text { Questions }\end{array}$ & $\begin{array}{c}\text { Total no. of } \\
\text { Students }\end{array}$ & $\begin{array}{r}\text { Avg. no. of Q. } \\
\text { Attempted }\end{array}$ & $\begin{array}{c}\text { Avg. } \\
\text { Marks } \\
\text { (Out of })\end{array}$ \\
\hline ESE & 12 & $25(26)$ & 9 & $\begin{array}{c}54.4 \\
(100)\end{array}$ \\
\hline
\end{tabular}

The values in Table 4 have delivered an intuition that the average number of questions attempted has not shown a markable upsurge but the average marks have grown with a slight impact of $6 \%$ rise compared to Unit Tests.

\section{Issues in Conducting the Techniques}

There are several issues faced during conduction of above said active learning strategies. Few of tangible issues are given as follows:

- Deficiency of related coverage in available case studies as per need

- Tracking absenteeism of group/peer members

- Management of time

The shortfall of content coverage was handled with hybridization of needful selected dimensions within related case studies. But the issues related to continuousness in attendance and time needs some strategic interventions.

\section{Conclusions}

Planned innovative methods based on active engagement of students were applied to three courses viz. Database management Systems, Big Data Analytics (Program Elective) and Machine Learning (Program Elective) at different graduation levels. Adapting active learning strategies namely Case study based Active Review Sessions and Skillathon have facilitated to engross large classrooms along with improving the learning outcomes. Case study based reviewing aspect has provided a 360 degree angle of overall class across the given assignments. It has moreover provided a stage-wise approach for more refinement with refining the discussed solution. Skillathon has concretely methodized to impart a wholesome view of entire syllabi while tracking the relation of concept with a unique answer. Involving students with real-time case studies and MCQ based tactic underlying competitive dais has attempted to experience a dynamic environment during concept delivery. Furthermore, the probability of attempting the questions related to certain block holes has improved improving course outcomes. Indirectly it has contributed to uplift the marks matrix. The intangible benefits of learning in team have reduced stress by preparing complex concepts over collaborative efforts.

\section{Acknowledgement}

The authors wish to thank Director-RIT, Dean-Academics and Head-CSE for their timely guidance and kind support throughout the practicing of these techniques and its qualitative built-up.

\section{References}

[1] Armbruster, P., Patel, M., Johnson, E., \& Weiss, M. (2009) Active Learning and Student-centered Pedagogy Improve Student Attitudes and Performance in Introductory Biology, CBELife Sciences Education, 8(3), 203-213.

[2] Prince, M. (2004) Does Active Learning Work? A Review of the Research, Journal of Engineering Education, 93(3), 223-231.

[3] Bransford J., Brown A., \& Cocking RR. (Eds.) (1999) How People Learn: Brain, Mind, Experience, and, Washington (DC): National Academy Press. 